2016-07

\title{
Boundary layer dynamics in the swash zone under large-scale laboratory conditions
}

\section{Ruju, A}

http://hdl.handle.net/10026.1/6287

10.1016/j.coastaleng.2015.08.001

COASTAL ENGINEERING

Elsevier BV

All content in PEARL is protected by copyright law. Author manuscripts are made available in accordance with publisher policies. Please cite only the published version using the details provided on the item record or document. In the absence of an open licence (e.g. Creative Commons), permissions for further reuse of content should be sought from the publisher or author. 


\section{CPRG Paper7}

\section{COASTAL \\ PROCESSES WITH \\ Coastal Processes Research Group \\ School of Marine Science and Engineering \\ University of Plymouth \\ Drake Circus \\ PLYMOUTH, PL4 8AA \\ United Kingdom}

Contact:

daniel.conley@plymouth.ac.uk

The Coastal Processes Research Group is an internationally recognised group of researchers, specialising in field studies of coastal processes. We aim to be a leading contributor to the international research community seeking to understand and predict the behaviour of coastal and estuarine systems in support of appropriate management of coastal resources and activities.

\section{Example Research Areas}

- beach morphodynamics and nearshore sediment transport

- coastal erosion and storm impacts

- video monitoring of coastal systems

- coastal process modelling

- $\quad$ estuarine processes and evolution

\section{Paper details}

\begin{tabular}{|c|c|}
\hline Citation & $\begin{array}{l}\text { Andrea Ruju, Daniel Conley, Gerd Masselink, Martin Austin, Jack Puleo, Thijs Lanckriet, Diane } \\
\text { Foster, Boundary layer dynamics in the swash zone under large-scale laboratory conditions, Coastal } \\
\text { Engineering, Volume 113, July 2016, Pages 47-61, ISSN 0378-3839, } \\
\text { http://dx.doi.org/10.1016/j.coastaleng.2015.08.001. }\end{array}$ \\
\hline Author(s) & $\begin{array}{l}\text { Andrea Ruju, Daniel Conley, Gerd Masselink, Martin Austin, Jack Puleo, Thijs Lanckriet, Diane } \\
\text { Foster }\end{array}$ \\
\hline Corresponding Author & andrea.ruju@plymouth.ac.uk \\
\hline Funding bodies & EPSRC (EP/K000306/1); EU 7th Framework Programme (HYDRALAB IV, contract no. 261520) \\
\hline Paper URL publisher & http://www.sciencedirect.com/science/article/pii/S0378383915001283 \\
\hline Date submitted & 08 October 20165 \\
\hline
\end{tabular}




\title{
Boundary layer dynamics in the swash zone under large-scale laboratory conditions
}

\author{
Andrea Ruju ${ }^{\mathrm{a}}$, Daniel Conley ${ }^{\mathrm{a}}$, Gerd Masselink ${ }^{\mathrm{a}}$, Martin Austin ${ }^{\mathrm{b}}$, Jack \\ Puleo $^{c}$, Thijs Lanckriet ${ }^{c}$, Diane Foster ${ }^{\mathrm{d}}$ \\ ${ }^{a}$ School of Marine Science and Engineering, Plymouth University, Drake Circus, \\ Plymouth, Devon, PL8 4AA, UK \\ ${ }^{b}$ School of Ocean Sciences, Bangor University, Menai Bridge, Anglesey, LL59 5AB, UK \\ ${ }^{c}$ Center for Applied Coastal Research, University of Delaware, Newark, DE 19716, USA \\ ${ }^{d}$ Dept. of Mech. Engin., W101 Kingsbury Hall, Univ. of New Hampshire, Durham, NH, \\ 03824
}

\begin{abstract}
This paper ${ }^{1}$ presents the results of a laboratory experiment of swash hydrodynamics on a coarse sand barrier beach backed by a lagoon. Boundary layer dynamics have been analyzed using the high-resolution near-bed velocities measured by Acoustic Doppler Velocity Profilers deployed in the swash zone. Swash events have been ensemble-averaged in order to study mean hydrodynamic patterns. A proposed velocity gradient criterion allowed identification of the boundary layer growth during the backwash phase but it was unable to characterize boundary layer variability during uprush. Cross-shore velocity profiles were well represented by the logarithmic model for a large portion of the ensemble-averaged swash duration. Uprush and backwash logarithmicestimated friction factors were of the same order of magnitude with a strong variability related to the boundary layer growth during the backwash. The momentum integral method provided smaller bed shear stresses than the logarithmic model, a result possibly related to either the assumptions involved in the momentum integral method or to an underestimation of the boundary layer thickness during uprush. A decrease of friction coefficients for increasing Reynolds numbers at the early backwash was observed. This behaviour is consistent with traditional results for steady and uniform flows in a transitional regime.
\end{abstract}

\footnotetext{
Email address: andrea.ruju@plymouth.ac.uk (Andrea Ruju)

${ }^{1}$ Authors version of: "Ruju, A., Conley, D.C., Masselink, G., Austin, M., Puleo, J.,
} 
Keywords:

Swash, Boundary layer, Laboratory experiments, Logarithmic model, Momentum integral model

\section{Introduction}

Nearshore waves propagate across the surf zone into shallower depths eventually washing up and down on the beach face. These direction-reversing flows, called uprush and backwash, characterize the swash zone motion and define the moving shoreline. Surf zone waves represent the first order forcing of swash motions which are subsequently affected by hydro- and morphodynamic factors such as nearshore currents, wind forcing, groundwater table fluctuations, beach morphology and sediment characteristics. Interactions between the hydrodynamics and the sandy bottom yield large vertical velocity gradients close to the seabed. As a result, wave energy dissipation occurs in a thin bottom boundary layer characterized by large shear stresses, high turbulence levels, and considerable sediment loads. The bed shear stress induced by boundary layer dynamics is of great importance for bringing sediment into suspension. Nowadays, widely-used morphological models implement sediment transport formulations which include the bed shear stress as the primary mechanism for sediment mobilization in the swash zone.

Observations of the structure of the bottom boundary layer in the swash zone have been reported by means of field, laboratory and numerical experiments. Recently, useful insights were yielded by the field work of Puleo et al. (2012) and Puleo et al. (2014a) who used a newly developed high resolution Acoustic Doppler Velocity Profiler (ADVP) to measure the cross-shore velocity profiles under low energetic swell forcing. The increased measurement resolution improved the characterization of the lower boundary layer kinematics and enhanced confidence in the estimated bed shear stress values. In addition to field observations, laboratory studies have taken advantage of controlled experiments in order to address swash dynamics under highly monitored systems (Archetti and Brocchini, 2002; Cowen et al., 2003). Recently, Barnes et al. (2009), O'Donoghue et al. (2010) and Kikkert et al.

Lanckriet, T., Foster, D. Available online 19 November 2015, Boundary layer dynamics in the swash zone under large-scale laboratory conditions, Coastal Engineering, ISSN 03783839, http://dx.doi.org/10.1016/j.coastaleng.2015.08.001" 
(2012) achieved high spatial resolution of the swash hydrodynamics over fixed, impermeable beds through Laser-induced Fluorescence (LIF) and Particle Image Velocimetry (PIV). In particular, Kikkert et al. (2012) were able to resolve the backwash shoreline position and the late backwash phase in which the shallow depths and large velocities challenge reliable data collection. In recent years, numerical models based on the Nonlinear Shallow Water (NLSW) and Reynolds-Averaged Navier-Stokes (RANS) equations have become a powerful tool to explore swash hydrodynamics. Barnes and Baldock (2010), Briganti et al. (2011) and Torres-Freyermuth et al. (2013) provided detailed descriptions of the boundary layer evolution in the swash zone by modeling the laboratory experiments of O'Donoghue et al. (2010).

Recent work dealing with swash zone motions has provided insightful description of boundary layer dynamics under a wide range of environmental conditions. However, the challenging swash zone environments in conjunction with the measurement technique limitations have led to the necessity of making considerable assumptions about the boundary layer structure. Several studies (Masselink et al., 2005; O'Donoghue et al., 2010; Puleo et al., 2012, 2014a) estimated the bed shear stress by fitting the horizontal velocity profiles close to the bed to a logarithmic model. The logarithmic model generally provided good agreement with measurements for a large portion of the swash but it performed less well during the uprush phase of swash in which aeration and surface-injected turbulence play an important role. Moreover there is no consensus about the relative magnitudes of the estimated friction factors during uprush and backwash. Kikkert et al. (2012) took advantage of the detailed measurements of velocity in an effort to compare bed shear stress estimations using different approaches such as the logarithmic and the momentum balance methods. Overall, past studies have outlined the necessity of high resolution velocity measurements for achieving a better estimation of bed shear stresses in the swash zone (Puleo et al., 2000; Butt et al., 2009; Alsina and Caceres, 2011). It has been recognized that a detailed description of the near-bed velocity field is crucial for a proper quantification of sediment fluxes that are ultimately estimated as the product of the velocity and sediment concentration measurements. In fact, despite the increasing attention that the swash zone dynamics have received in the last decade, a complete understanding and characterization of swash boundary layer motions and sediment transport processes is still lacking.

This work reports measurements of swash hydrodynamics collected during recent laboratory experiments carried out in a large-scale wave flume 
(Masselink et al., 2015). We report high resolution cross-shore velocity profiles recorded in the swash boundary layer of a sandy beach under irregular wave conditions. The main aim of this paper is to take advantage of the high resolution measurement dataset obtained under controlled laboratory experiments to improve the characterization of boundary layer dynamics. In particular, bed shear stress is inferred by means of logarithmic and momentum integral methods and the two approaches are compared and discussed. In addition, friction factor patterns for different swash phases, separate locations in the swash zone, varying degrees of bed saturation and different Reynolds numbers are analyzed.

The paper is organized as follows. Section 2 provides a review of the most common theories and approaches used for boundary layer dynamics and bed shear stress characterization. The methods including the description of the laboratory experiments and the data analysis techniques are provided in section 3. Section 4 and 5 present and discuss the laboratory results. Section 6 outlines some conclusions.

\section{Boundary layer velocity profiles and bed shear stresses}

\subsection{The momentum integral method}

In the case of horizontal uniform flow, the momentum conservation equations for the boundary layer read:

$$
\begin{gathered}
\rho \frac{\partial u}{\partial t}=-\frac{\partial p}{\partial x}+\frac{\partial \tau}{\partial z} \\
\frac{\partial p}{\partial z}=-\rho g
\end{gathered}
$$

where $u$ is the horizontal velocity, $t$ is the time, $p$ is the pressure, $\tau$ is the shear stress, $g$ is the gravitational acceleration and $\rho$ is the water density. Equations (1) and (2) imply that inside the boundary layer the pressure is hydrostatic and the longitudinal pressure gradient $\partial p / \partial x$ is constant across the boundary layer thickness. By assuming that the shear stress vanishes outside the boundary layer, it is possible to write the horizontal momentum equation on the top of the boundary layer as:

$$
\frac{\partial p}{\partial x}=-\rho \frac{\partial U_{0}}{\partial t}
$$


where $U_{0}$ represent the free stream velocity (see figure 1 providing a sketch with the relevant variables). By inserting equation (3) into equation (1), the defect velocity law (Nielsen, 1992; Fredsøe and Deigaard, 1992) describing the evolution of the boundary layer is obtained:

$$
\rho \frac{\partial}{\partial t}\left(U_{0}-u\right)=-\frac{\partial \tau}{\partial z}
$$

The bed shear stress $\tau_{b}$ can be obtained by integrating this equation across the boundary layer thickness $\delta$ :

$$
\tau_{b}=\rho\left(\delta \frac{\partial U_{0}}{\partial t}-\int_{z_{0}}^{z_{0}+\delta} \frac{\partial u}{\partial t} d z\right)
$$

Two main assumptions are involved in the derivation of equation (4) and (5) from the general momentum conservation equations. The first assumption concerns the flow uniformity leading to negligible advective terms and dynamic pressure in the boundary layer. A zero shear stress at the top of the boundary layer represents the second assumption. It is worth mentioning that in the swash zone the boundary layer thickness is not much smaller than the water depth $h$ (Puleo and Holland, 2001). In case the boundary layer covers the entire swash depth, the assumption of $u(h)=U_{0}$ is considered (Briganti et al., 2011).

As already stated, the momentum integral method assumes a hydrostatic pressure field inside the boundary layer; in case pressure can be considered hydrostatic across the whole swash zone water column, equation (3) can be replaced by:

$$
\frac{\partial p}{\partial x}=\rho g \frac{\partial \eta}{\partial x}
$$

where $\eta$ is the free surface elevation. Equation (6) leads to an alternative version of the momentum integral equation:

$$
\tau_{b}=\rho\left(-\delta g \frac{\partial \eta}{\partial x}-\int_{z_{0}}^{z_{0}+\delta} \frac{\partial u}{\partial t} d z\right)
$$

Herein, equation (5) and (7) are referred to as MIM_$U_{0}$ and MIM_$\eta$. The performance of the two versions of the momentum integral method relies upon the capacity of estimating the pressure gradient $\partial p / \partial x$ inside the boundary layer. It is important to point out that different assumptions are considered into equations MIM_$U_{0}$ and MIM_$\eta$. In fact, MIM_$\eta$ assumes a hydrostatic pressure field across the entire swash water column; whereas, equation 
MIM_ $U_{0}$ requires negligible shear stresses at the top of the boundary layer. Nielsen (2002) used the local acceleration $\partial U_{0} / \partial t$ as a proxy to $\partial p / \partial x$. On the other hand, Baldock and Hughes (2006) and Barnes and Baldock (2010) suggested that, since flow decelerates for most of the swash event, $\partial p / \partial x$ can be calculated using the hydrostatic assumption through the free surface gradient $\partial \eta / \partial x$ (see also Othman et al. (2014) who provided additional discussion). However, it is still not clear a priori which of these two approaches is more reliable for the estimation of $\partial p / \partial x$ inside the swash boundary layer.

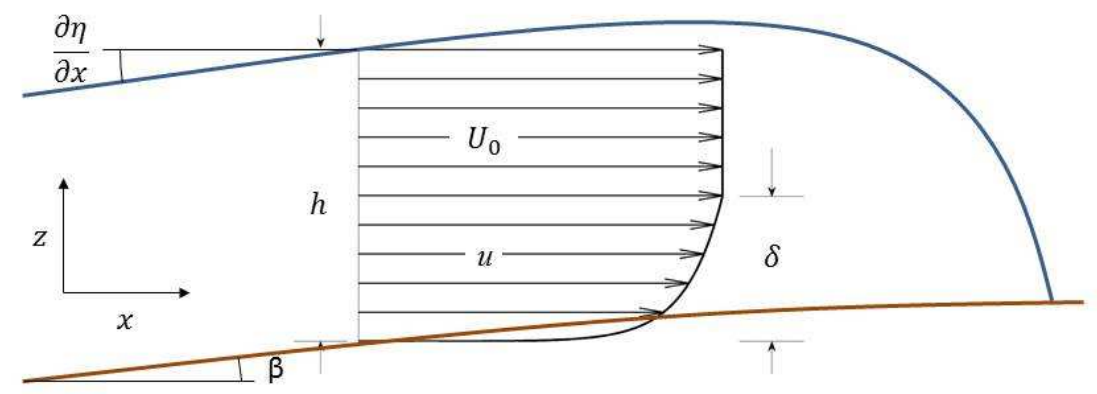

Figure 1: Sketch of the parameters involved in the swash zone model equations.

\subsection{Logarithmic model}

In the case of a hydraulically rough bed, the law of the wall prescribes that a logarithmic-shaped horizontal velocity profile $u(z)$ develops inside the boundary layer:

$$
u(z)=\frac{U_{f}}{\kappa} \ln \left(\frac{z}{z_{0}}\right)
$$


where $\kappa$ is the von Karman constant $(=0.40)$ and $z_{0}$ is the height above the bed at which the velocity is assumed to be zero. Following Nikuradse (1932), $z_{0}$ is equal to $k_{N} / 30, k_{N}$ being the bed roughness. Finally, $U_{f}$ is the friction velocity defined as:

$$
U_{f}=\sqrt{\frac{\tau_{b}}{\rho}}
$$

where $\tau_{b}$ is the bed shear stress and $\rho$ is the water density.

Equation (8) was originally derived for steady flows assuming that shear stresses are constant close to the bottom. These assumptions, on which the law of the wall relies, restricts its theoretical validity to a region whose vertical extent above the bottom depends on the non-dimensional elevation $z^{+}$defined as:

$$
z^{+}=\frac{U_{f} z}{\nu}
$$

where $\nu$ is the kinematic viscosity $\left(\nu=10^{-6} \mathrm{~m}^{2} / \mathrm{s}\right)$. According to Pope (2000) and Wei and Willmart (1989), the law of the wall holds for $30<z^{+}<1200$. However, experimental work has found good agreement between observed and predicted data well beyond the range of applicability of the logarithmic model.

The concept of friction factor $f$ has been introduced in order to relate the free stream horizontal velocity $U_{0}$ to the bed shear stress by means of:

$$
\tau_{b}=\frac{1}{2} \rho f\left|U_{0}\right| U_{0}
$$

When velocity profile information is not available, the bed stress $\tau_{b}$ is estimated through equation (11), also known as the quadratic drag law, by introducing an empirical value of $f$. For instances in which velocity profile measurements are available, $f$ can be estimated as:

$$
f=\frac{2 \tau_{b}}{\rho\left|U_{0}\right| U_{0}}
$$

\section{Methods}

\subsection{Laboratory Experiments}

The laboratory experiments included in the BARDEX II project were carried out in the Delta flume (The Netherlands). In this section, we outline the experimental details relevant for this work; an exhaustive description of 
the experiments is provided by Masselink et al. (2015). The Delta flume is $200 \mathrm{~m}$ long, $5 \mathrm{~m}$ wide and $7 \mathrm{~m}$ high with an hydraulically-driven piston-type wave maker located at one end of the flume. The physical model consisted of a sandy barrier beach with a median grain diameter of $0.43 \mathrm{~mm}$, backed by a lagoon. The still water depth in the constant depth generation section in front of the wave maker was set at $3 \mathrm{~m}$. The original beach profile included a horizontal bottom part and a slope-varying part. The undisturbed shoreline lay at $86.5 \mathrm{~m}$ from the neutral position of the wave maker. The beach had a slope 1:15 in the surf and swash zone reaching the top of the berm localized $1.5 \mathrm{~m}$ above the still water level. A permeable wall separated the sandy barrier from the lagoon. The size of the laboratory facilities allowed the full-scale reproduction of moderate wave conditions with the chief advantage of avoiding typical scale effects and associated shortcomings involved in small scale physical tests such as, for instance, a reduced suspended sediment transport rate and an overestimation of frictional effects (Sanchez-Arcilla et al., 2011; Masselink et al., 2015). The origin of the co-ordinate system was fixed at the intersection of the mean position of the wave maker with the concrete bottom, with the horizontal and vertical axes positive shoreward and upward, respectively.

The beach profile elevations at $2.5 \mathrm{~m}$ from the lateral walls of the flume (center of the flume) were measured at the end of each run by a high resolution mechanical beach profiler controlled by means of a overhead carriage. In this work we discuss the swash measurements collected at two stations located at $x=88.4 \mathrm{~m}$ (Station 1) and $x=89.6 \mathrm{~m}$ (Station 2). Near-bed velocities were collected using Nortek Acoustic Doppler Velocity Profilers (ADVP) that measured the 3 components of velocity in a profile $3 \mathrm{~cm}$ long with $0.001 \mathrm{~m}$ vertical resolution and a sampling frequency of $100 \mathrm{~Hz}$. The water free surface elevations were recorded by a Bed Level Sensor (BLS) array covering the whole swash zone extension with a horizontal spatial resolution of approximately $0.7 \mathrm{~m}$. Within-bed pressure gradients were measured by pressure transducers Druck PTX1830 (PT) buried in the swash zone in the vicinity of Station 2. Due to morphological changes, frequent manual adjustments both in the vertical and in the horizontal direction were performed in order to keep the highest PT as close as possible to the bed (between 2 and 5 $\mathrm{cm}$ ). Figure 2 shows the beach profiles corresponding to the 2 runs studied in this paper (the beach profile for a determined run is obtained as the average between the profiles measured prior and after the run) with the observed still water line and the indication of the cross-shore location of Station 1 and 


\section{Station 2.}

In this paper we focus on the 30 min-long runs with random waves A2_05 and A4_05 (Masselink et al., 2015). The wave generation signal used to control the wave maker movement was irregular but deterministic, allowing the reproduction of the same incoming wave sequence and group structure in these runs. The target irregular wave conditions matched a JONSWAP spectrum with significant wave height $0.8 \mathrm{~m}$ and peak period of $8 \mathrm{~s}$. Active reflection compensation was used to absorb outgoing waves and minimize reflection at the wave maker. The difference between the runs was the mean water level in the lagoon. Run A2_05 represents a high lagoon scenario in which the level in the lagoon $(4.5 \mathrm{~m})$ is higher than the sea level; on the other hand, the lagoon level $(2.25 \mathrm{~m})$ in run A4_05 is lower than the mean sea level. Moreover, wave action steepened the beach face and built a berm during the A series (Puleo et al., 2015) yielding a slightly larger beach slope in the later run A4_05.
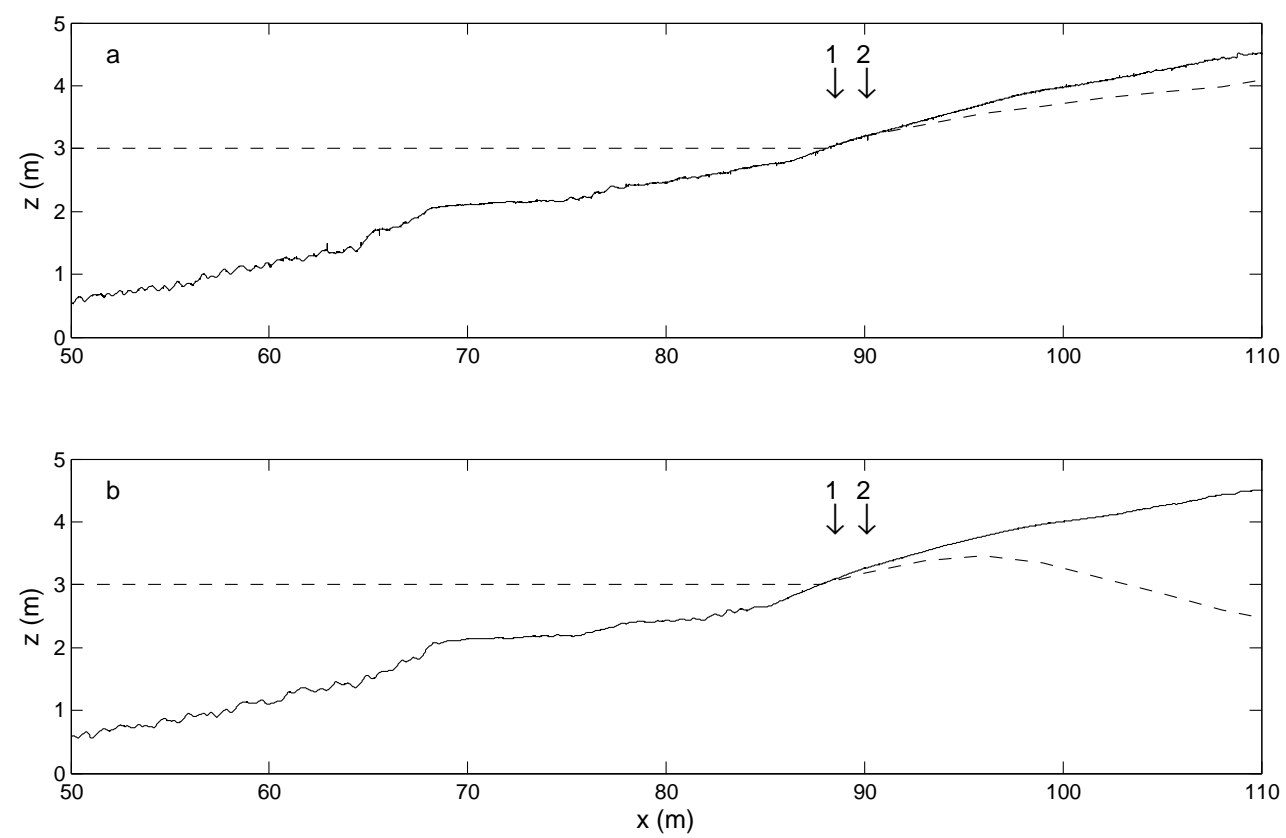

Figure 2: Beach profile during run A2_05 (a) and A4_05 (b). The dashed line represents the mean free surface and water table measured by the PT array along the flume. Vertical arrows indicate the location of Station 1 and 2. 


\subsection{Data analysis}

The complexity of shallow-water hydrodynamics makes the collection of reliable experimental observations across the swash zone difficult. Data analysis is further hampered by its intermittent nature, precluding the application of conventional time series analysis such as spectral analysis, and making critical comparisons between theory and observations difficult (Hughes and Baldock, 2004). Nevertheless, especially in the last decade, swash zone processes have represented a highly active research area. Developments in measurement technology have resulted in an increase in data availability and accuracy (O'Donoghue et al., 2010; Kikkert et al., 2012; Puleo et al., 2012). Moreover, robust data-analysis techniques have been developed in order to better understand and characterize swash processes (Puleo et al., 2012).

The discontinuous nature of swash hydrodynamics together with the high amount of foam, bubbles and sediment loads lead to the necessity of a quality check for assessing data reliability before performing an analysis of near-bed swash velocity measurements. In this work, ADVP data were removed from the record when at least one of the two following circumstances occurred (Aagard and Hughes, 2006; Puleo et al., 2012): 1) the instantaneous (averaged over the four beams) Correlation (Corr) values were less than 65\%; 2) the instantaneous (averaged over the four beams) Signal-to-Noise-Ratio (SNR) values dropped below 20. These criteria appeared to be appropriate for removing unreliable data associated with air-entrainment, bubbles and large sediment concentrations. The removed data were not replaced by any interpolation due to the intermittent nature of swash. In addition, the velocity time series were de-spiked using the method proposed by Mori et al. (2007) in order to eliminate noise and spurious data points. Successively, an interpolation procedure was used to reduce the sampling frequency from 100 to $16 \mathrm{~Hz}$. This new sampling value is sufficient for addressing swash hydrodynamic analysis as it is 2 orders of magnitude larger than the peak frequency of the incoming wave field.

Swash zone elevations at a determined cross-shore position are identified from free surface data measured by the BLS array. This array covered the whole swash zone but, to avoid signal interference, the BLS measurements were not co-located with the swash stations where the ADVP were deployed. In order to obtain the free surface elevations at the same cross-shore position of the associated ADVP at a determined station, the two BLS time series at either side of the swash station were linearly interpolated. The water depth during a swash flow event is determined by subtracting the BLS data 
value recorded when the bed was exposed previously to the bore arrival from the instantaneous free surface elevation. Swash events are defined to begin when the water depth reaches one tenth of the maximum water depth recorded during the event, corresponding with the bore front arrival; whereas the instant on which the water depth drops below one tenth of the maximum water depth is considered as the event end. An elevation cut-off based on the maximum swash depth is chosen here with the main purpose of including in the analysis the late backwash phases of relatively small events which would be otherwise excluded by using a constant cutoff value. To have consistent time series, the BLS observations were resampled at $16 \mathrm{~Hz}$ as done for ADVP data. Whilst the BLS data were used for event identification, the time of flow reversal was evaluated using the ADVP data. The time of flow reversal for each event was assumed to coincide with the instant when the velocity at the upper most bin turns from positive to negative values. Therefore, uprush (backwash) durations are the absolute value of the difference in time between the flow reversal and the beginning (end) of the event.

Figure 3 shows the free surface elevation with respect to the concrete bottom (vertical reference of the tank) and cross-shore velocity time series for two swash events of run A2_05. There is a distinct lack of reliable velocity measurements at the beginning of the uprush and at the end of backwash. This can be partially ascribed to the data cleaning process which removed noise and unreliable data generally associated with air-entrainment, bubbles and sediment suspension particularly influential during these stages of swash. It also represents fluid depth insufficient to permit sensor operation.

In this work, the bed location for each swash event was determined as being the highest bin where both the mean and standard deviation of velocity (calculated across the event) are less than a cutoff value of $0.05 \mathrm{~m} / \mathrm{s}$. The application of this technique implies that the bed location is assumed to remain constant over the duration of the event. Even though Puleo et al. (2014a) showed that intra-swash bed fluctuations can be significant, the evaluation of their effects is beyond the scope of the present work and we consider here a steady bed elevation within the swash events. In addition, the bed elevation was also checked with the SNR and Amplitude (AMP) signals averaged over the four beams. Other studies used the highest SNR and AMP values in order to estimate the time-varying bed level (Foster et al., 2013; Puleo et al., 2014b). For these conditions, the SNR and AMP cutoff values were determined to be 57.5 and $-7 \mathrm{~dB}$, respectively. Figure 4 shows a closer examination of velocity and bed location over the same two swash events plotted 

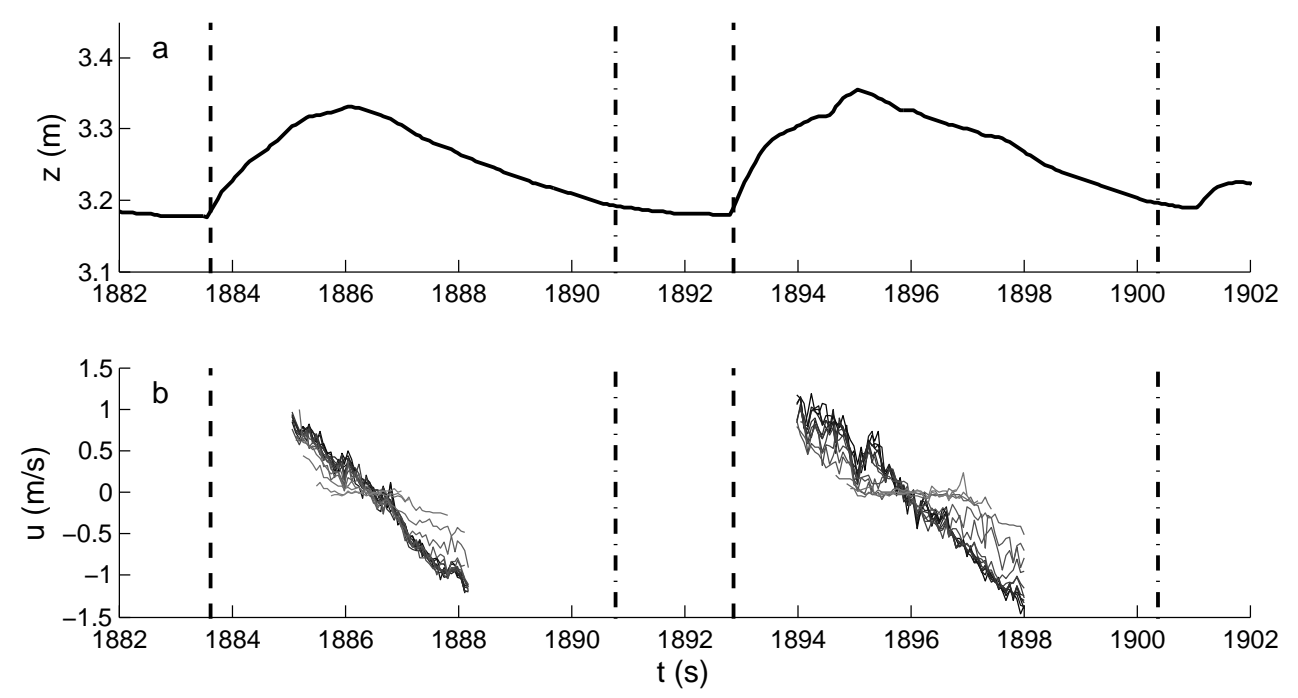

Figure 3: Time series of free surface elevation (a) and horizontal cross-shore velocities (b) detected during run A2_05 at Station 1. Two swash events are delimited by vertical dashed lines. Each trace in the cross-shore velocities represents measurements at different elevations from the sandy bed. The darker the line the larger the distance from the bed.

in figure 3. The $z_{A}$ axis in figure 4 represents the vertical distance from the ADVP location. During the uprush, bottom estimates from ADVP parameters SNR and AMP are characterized by a considerable spread possibly related with the high turbulence levels induced by the incoming bore. Except in this early stage of uprush, bed location estimates from velocity statistics are largely consistent with those obtained from the SNR and AMP methods, thus confirming the adequacy of the standard deviation cutoff method. Later on in this work we consider the bed location as that one determined using the velocity statistic criterion.

From the whole ensemble of identified events in a run case, only the events meeting determined criteria were considered "good" and therefore retained for analysis (Puleo et al., 2012). The criteria utilized here were: 1) velocity profile intersecting the bed; 2) event duration larger than $3 \mathrm{~s}$; 3) uprush and backwash flow duration larger than $1 \mathrm{~s}$; and 4) maximum uprush and backwash velocities larger than $0.5 \mathrm{~m} / \mathrm{s}$.

In previous work involving irregular waves, an ensemble average of swash events was determined in order to study mean swash hydrodynamics (Puleo et al., 2000; Aagard and Hughes, 2006; Conley and Griffin, 2004; Masselink 

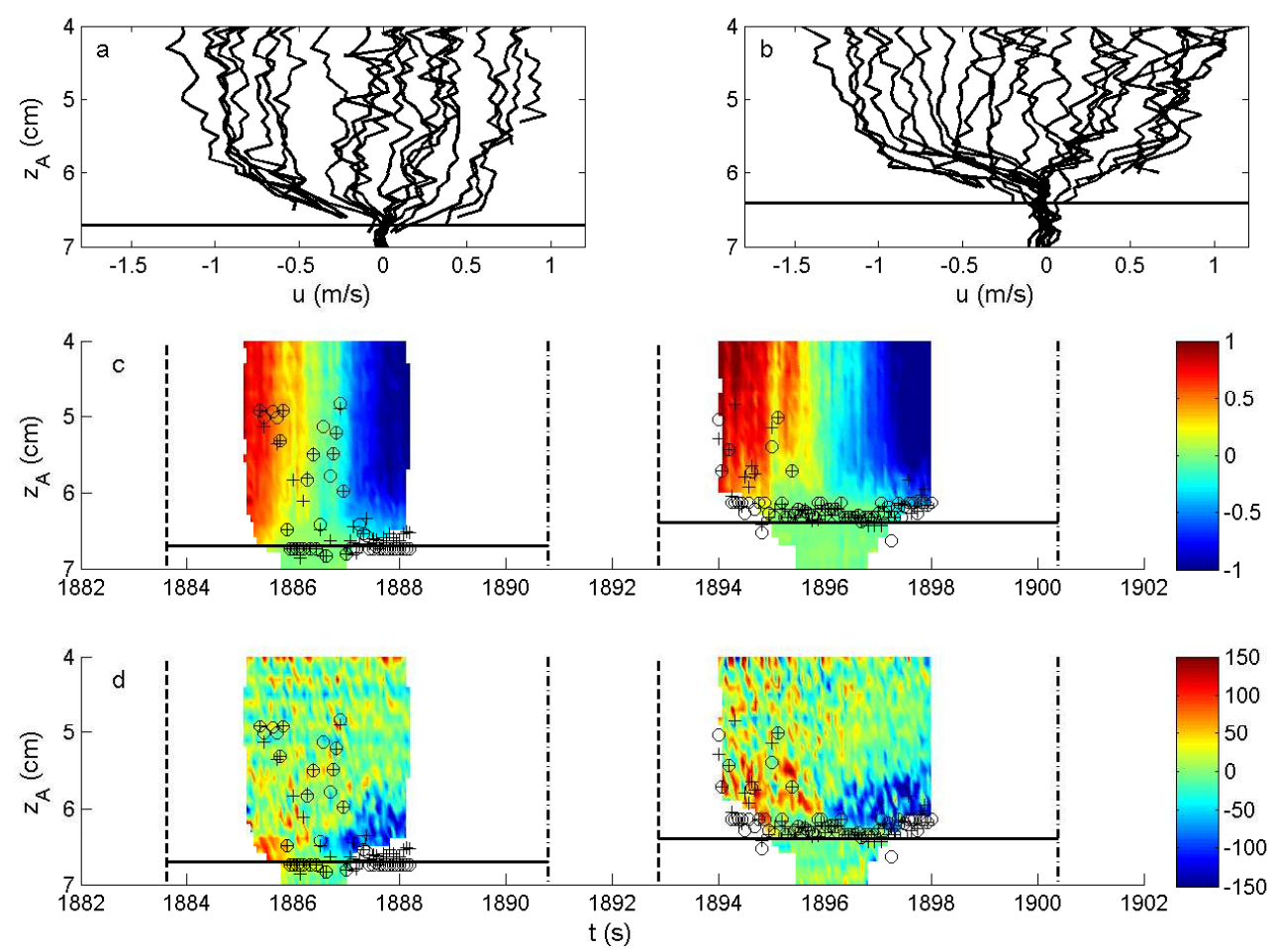

Figure 4: Location of the bed determined when the standard deviation of cross-shore velocity drops below $0.05 \mathrm{~m} / \mathrm{s}$ (horizontal straight line). a) and b) Vertical profiles of crossshore velocity for two events. c) Time series of cross-shore velocity $[\mathrm{m} / \mathrm{s}]$ as a function of distance below the ADVP. d) vertical gradient of cross-shore velocity $[1 / \mathrm{s}]$. Circles and crosses in c) and d) are the bed location estimates from the SNR and AMP parameters, respectively.

et al., 2005; Puleo et al., 2012). In particular, Puleo et al. (2012) carried out the ensemble average based on the timing relative to flow reversal with the aim to maintain the phases of flow. An analogous technique was also performed in the present study in which the normalization was based on the timing relative to flow reversal identified from ADVP data. In contrast, the uprush and backwash durations (and thus the event duration) were determined using the timing from BLS data. This procedure allowed to maintain the phases of fluid motion relative to both the actual event duration recorded by the BLS and the time reversal recorded by the ADVP. The ensemble-averaged duration $T$ was introduced as the sum between the 
averaged uprush $\left\langle D_{u p}\right\rangle$ and backwash $\left\langle D_{\text {back }}\right\rangle$ durations:

$$
T=\left\langle D_{u p}\right\rangle+\left\langle D_{b a c k}\right\rangle
$$

The dimensional normalized time $t_{n}$ was defined as:

$$
t_{n}=\left[\frac{t-t_{\text {rev }}}{D_{u p}}\left\langle D_{u p}\right\rangle ; \frac{t-t_{\text {rev }}}{D_{\text {back }}}\left\langle D_{\text {back }}\right\rangle\right]
$$

where $t_{\text {rev }}$ is the instant of flow reversal, $D_{\text {up }}$ and $D_{\text {back }}$ are the duration of uprush and backwash. Finally, the non-dimensional time $t^{\prime}$ was:

$$
t^{\prime}=\frac{t_{n}}{T}
$$

As a result of this normalization procedure, the non-dimensional uprush timing is negative and is bound to $\left[-\frac{\left\langle D_{u p}\right\rangle}{T}, 0\right]$, whereas the non-dimensional backwash timing takes positive values and extends between $\left[0, \frac{\left\langle D_{\text {back }}\right\rangle}{T}\right]$. Therefore, the normalized event has duration equal to 1 extending between $[-$ $\left.\frac{\left\langle D_{u p}\right\rangle}{T}, \frac{\left\langle D_{\text {back }}\right\rangle}{T}\right]$. This normalization method leads to a backwash duration which is likely to exceed the uprush duration as a result of the skewed and pitched-forward shape of swash bores.

The ensemble average value $v^{\prime}$ for a depth- and time-dependent variable $v$ in the normalized time-space domain $\left\langle t^{\prime}, z\right\rangle$ is defined as:

$$
v^{\prime}\left(t^{\prime}, z\right)=\frac{1}{N} \sum_{n=1}^{N} v_{n}\left(t^{\prime}, z\right)
$$

where $N$ is the number of events in which the variable $v\left(t^{\prime}, z\right)$ exists (is a real number). $N$ varies across the $\left\langle t^{\prime}, z\right\rangle$ domain: ranging between the total number of identified events and tending to 0 at the early uprush and late backwash where the lack of reliable velocity data is due to the cleaning procedure. This reflects what is evident for the individual events in figure 3. Ensemble-average values associated with $N$ lower than 8 were excluded. Variables such as velocity $u$, vertical velocity gradient $\partial u / \partial z$, water depth $h$, barrier pressure $p$, and free surface gradient $\partial \eta / \partial x$ were directly combined into an ensemble-averaged event representing mean flow patterns. On the 
other hand, acceleration $\partial u / \partial t$ was first estimated from the velocity time series slope by fitting a straight line to overlapping one-second windows (Foster et al., 2013) and then averaged into the normalized event.

The equations for the boundary layer are based on the assumption that in the immediate neighborhood at the top of the boundary layer, shear stresses vanish and $\partial U_{0} / \partial z \rightarrow 0$ (Fredsøe and Deigaard, 1992). In this work, the ensemble averaged vertical gradient of velocity is used to estimate the location of the top of the boundary layer and therefore its thickness. The free stream is assumed to extend above the top of the boundary layer where the local velocity gradients are lower than a small fraction of a reference velocity gradient representative of the ensemble averaged event:

$$
\frac{\partial u}{\partial z}<c \frac{\Delta u}{\Delta z}
$$

where the reference velocity $\Delta u$ is the maximum horizontal velocity observed during the averaged event, $\Delta z$ is the difference between the highest and the lowest sampling locations ( $3 \mathrm{~cm}$ in this work) and $c$ is a constant which was set equal to 0.2 here. A sensitivity analysis performed varying $\mathrm{c}$ between 0.15 and 0.25 showed negligible differences in the boundary layer thickness estimates.

\section{Results}

\subsection{Logarithmic model}

The logarithmic model is applied to the time series of cross-shore velocity for individual swash events. Figure 5 shows the evolution of a representative raw event selected from run A2_05 at Station 1. The $z_{b}$ axis in figure 5 and in the rest of the paper represents the vertical distance from the sandy bed. The time series of water elevations and cross-shore horizontal velocity at $0.02 \mathrm{~m}$ from the bottom are plotted in figures $5 \mathrm{a}$ and $5 \mathrm{~b}$, respectively. Figure $5 \mathrm{c}$ shows the velocity profiles from 24 evenly spaced times during the whole duration of the raw event. The free surface elevation increases rapidly during the uprush as the bore front hits the measurement location; after the maximum water depth, a mild free surface elevation reduction is observed. As a result of the quality control procedure, the velocity profiles cover only $42 \%$ of the swash event. The measured flow velocities at $0.02 \mathrm{~m}$ from the bottom show an uprush peak of $0.8 \mathrm{~m} / \mathrm{s}$ and a backwash maximum of 1.2 $\mathrm{m} / \mathrm{s}$. Past studies used an $r^{2}$ cut-off of 0.9 to indicate poor logarithmic model 
fit (O'Donoghue et al., 2010; Puleo et al., 2012). However, due to significant velocity fluctuations, the $r^{2}$ cut-off is reduced to 0.8 here for the raw event. The logarithmic model accurately describes $35 \%$ of the observed velocity profiles of this raw event. Poor model fits particularly occur during the flow reversal when velocities are small across the entire water column.
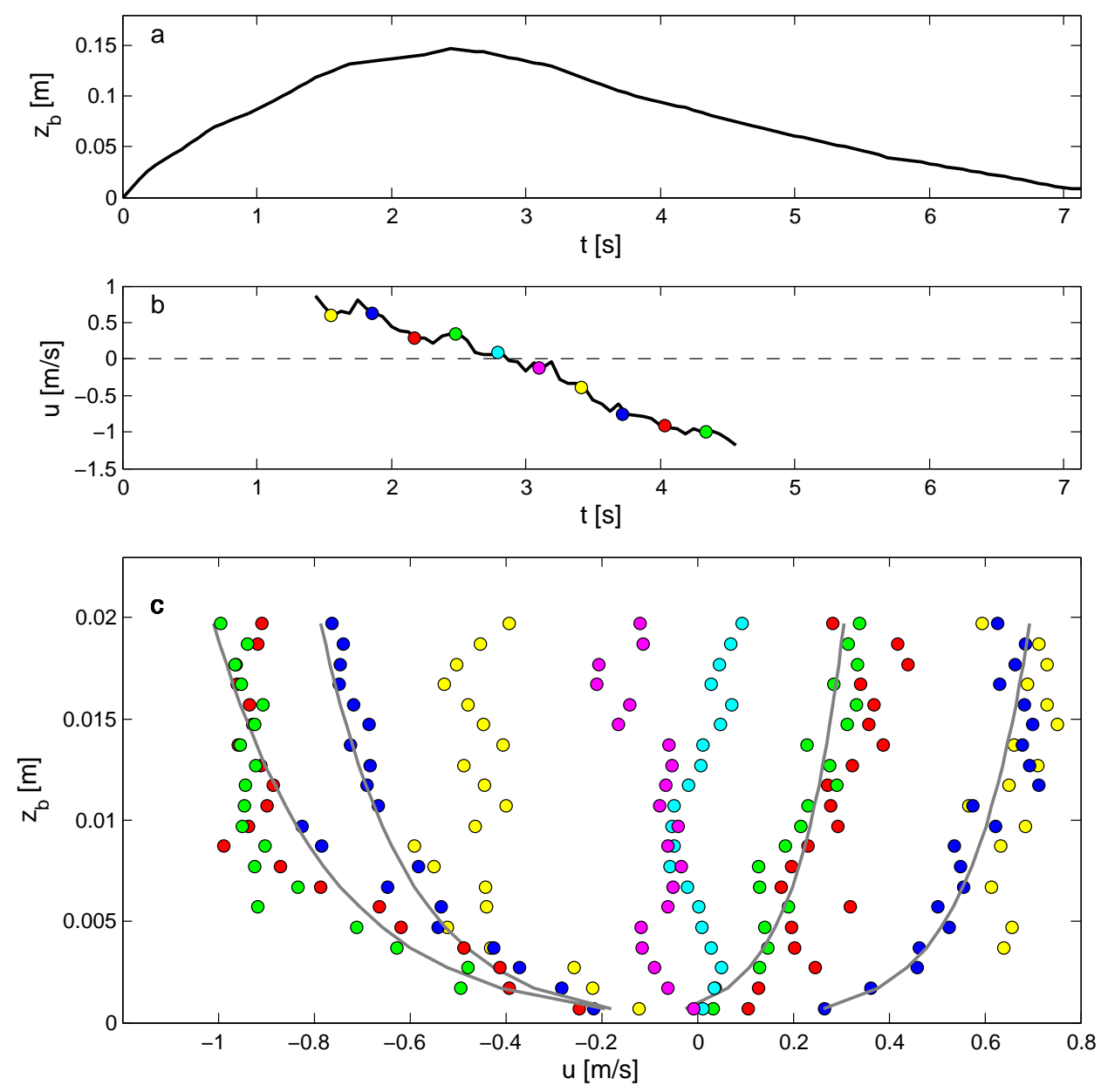

Figure 5: Raw event of run A2_05 at Station 1. a) water depths and b) velocity time series at $2 \mathrm{~cm}$ from the bed. Vertical profiles of velocity (c) with solid lines indicating the logarithmic model fits. 
Figure 6 shows the flow velocity, acceleration and velocity gradient fields for the ensemble averaged event for run A2_05 at Station 1. A total number of 94 events were included in the normalization process. The mean periods of these "good" events is $6.7 \mathrm{~s}$ with a minimum and maximum values of 3.7 and $11.4 \mathrm{~s}$, respectively. As a result of the ensemble average process, the velocity data exists for $82 \%$ of the total swash duration. Close to the bed, the low velocity and acceleration values in conjunction with high vertical velocity gradients outline the presence of a bottom boundary layer. As explained in section 3.2, the boundary layer extension $\delta$ is estimated as the region where the vertical velocity gradients exceed the threshold value $0.2 \Delta u / \Delta z$ $\mathrm{s}^{-1}$. However, a considerable temporal and spatial variability of velocity gradients is found across the water column during the uprush, which is likely to be related to the high turbulence levels contained within by the incoming bore. This significant mixing precludes the identification of a stable upper limit of the boundary layer during the uprush. Puleo et al. (2012) carried out a bed shear stress estimation in the swash zone of a natural beach by extending the logarithmic model to a region of $2 \mathrm{~cm}$ from the sandy bed. On the other hand, the numerical analysis of Briganti et al. (2011) and Torres-Freyermuth et al. (2013) suggested that the (logarithmic) boundary layer extends to a large part of the water column during uprush under the laboratory experiments described by O'Donoghue et al. (2010). For this reason we choose here a representative constant uprush $\delta$ equal to $2.7 \mathrm{~cm}$, corresponding to uppermost measurement elevation of the ensemble-averaged event during uprush, with the main purpose of delimiting the domain where the logarithmic and momentum integral models are applied. At flow reversal, velocity gradients are small and a thin boundary layer is observed. A gradual growth occurs during the backwash where the boundary layer extends up to the upper limit of the velocity observations.

The ensemble-averaged time series of water depths and cross-shore velocities at $2 \mathrm{~cm}$ from the bottom are plotted in figure $7 \mathrm{a}$ and $7 \mathrm{~b}$, respectively. Due to the skewed shape of of the swash time series, the backwash duration is longer than the uprush duration; the nondimensional time ranging between -0.47 to 0.53 . In addition, negative accelerations dominate the normalized swash event as a result of the pronounced wave-asymmetry. Logarithmic model fits to velocity profiles extending up to a constant elevation of $2 \mathrm{~cm}$ from the bottom are plotted in figure $7 \mathrm{c}$. The ensemble-averaged event is generally well described by the logarithmic model, with $r^{2}$ exceeding 0.9 for $60 \%$ of the total swash duration (corresponding to $73 \%$ of the measured ve- 

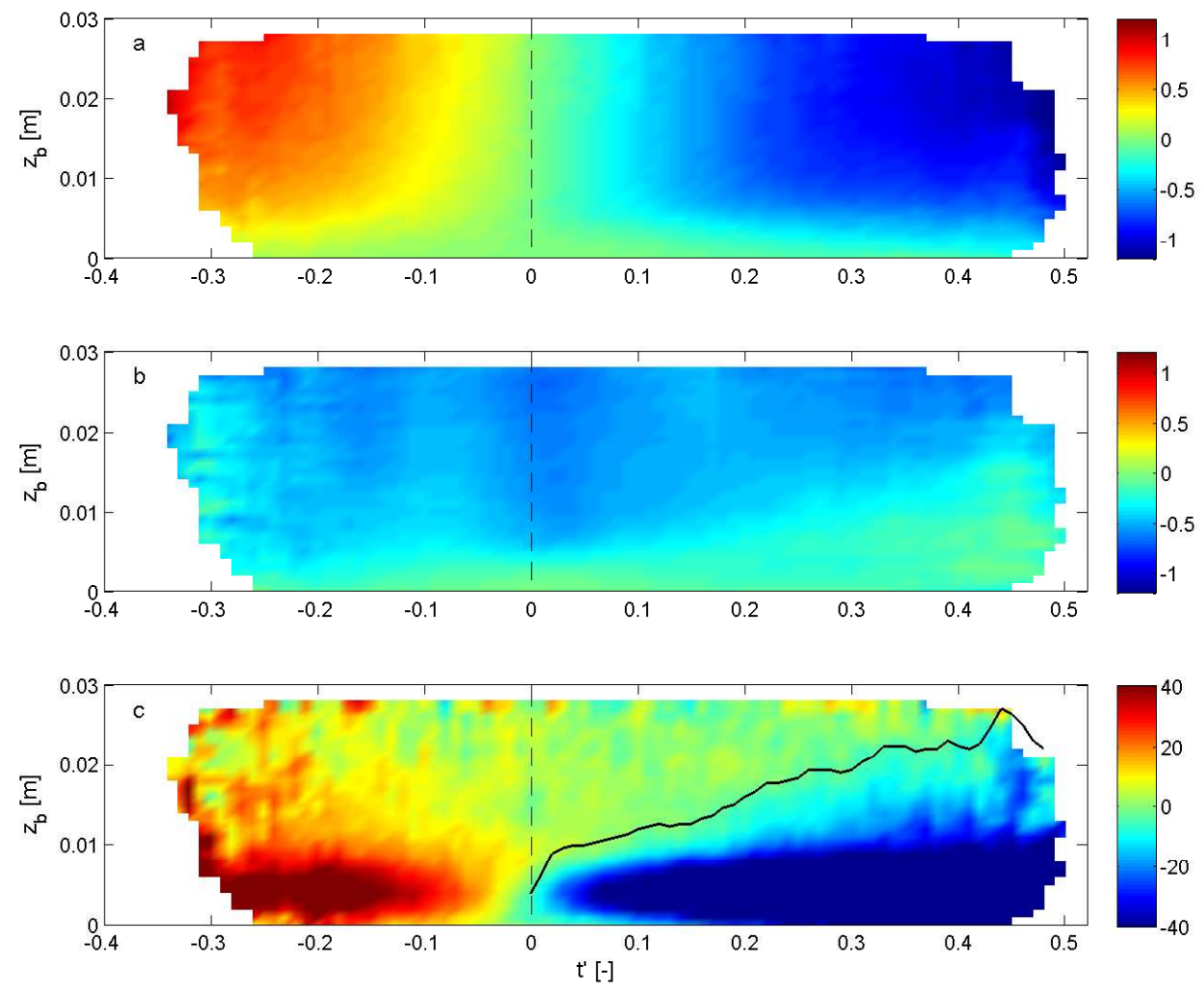

Figure 6: Ensemble-averaged swash event of run A2_05 at Station 1. a) cross-shore horizontal velocity $[\mathrm{m} / \mathrm{s}]$; b) accelerations $\left[\mathrm{m} / \mathrm{s}^{2}\right]$; and c) vertical gradient of velocity $[1 / \mathrm{s}]$. The black solid line indicates the boundary layer thickness estimated through the vertical gradient velocity threshold.

locity profiles). Poor model fits are observed at flow reversal and at the early stages of backwash. Figure $7 \mathrm{~d}$ shows the logarithmic model applied to the velocity profiles extending over the time-varying boundary layer thickness $\delta$. The portion of time during which $r^{2}$ exceeds 0.9 is increased (with respect to the constant boundary layer thickness) to $67 \%$ of the total swash duration or $82 \%$ of the observed velocity profiles. In particular, poor model fits are limited to the flow reversal when velocities tend to zero. As the boundary layer grows after flow reversal, the velocity profiles are well represented by the logarithmic model for almost the entire backwash duration.

In addition to a larger portion of swash velocity profiles fitted by the log- 



Figure 7: Ensemble-averaged swash event, run A2_05 at Station 1. a) water depths; b) velocity time series at $2 \mathrm{~cm}$ from the bottom; c) and d) velocity profiles. Non-filled circles are section of velocity profiles lying above $\delta$. Grey solid curves are logarithmic model fits. 



Figure 8: Hydrodynamic parameters estimated from the logarithmic model fit extended up to $2 \mathrm{~cm}$ (crosses) and to the boundary layer thickness estimated through the vertical gradient velocity threshold (circles), run A2_05 at Station 1. a) bed shear stress; b) free stream velocity; c) friction factor.

arithmic model, significant differences in the bed shear stress estimation can be noticed by taking into account the boundary layer thickness variability. Figure 8 shows the hydrodynamic parameters estimated through the logarithmic model. Regardless of the boundary layer thickness, the logarithmic model provides a bed shear stress which varies from a maximum value of 
$8 \mathrm{~N} / \mathrm{m}^{2}$ observed at the early uprush to a negative maximum of $-14 \mathrm{~N} / \mathrm{m}^{2}$ towards the end of the backwash. However, including the boundary layer growth during the backwash yields larger values of the bed shear stress for $t^{\prime}<0.25$. This is the result of excluding from the logarithmic fit the points of the profile characterized by small vertical gradients of velocity which are likely to lie above the bottom boundary layer, see equation (17). The small vertical gradients of velocity in the upper part of the water column far from the bottom lead to free stream velocity values which are not affected by the choice of the boundary layer thickness. As a result, the friction factors along the swash event reflect the bed shear stress pattern. Extending the logarithmic model fit up to $2 \mathrm{~cm}$ yields an almost constant friction factor of approximately a 0.025 . On the other hand, the larger bed shear stresses observed during the early backwash yield larger friction factors after flow reversal. In fact, a decreasing friction factor is observed coincident with a growing boundary layer during backwash.

\subsection{Momentum integral model}

Figure 9 shows the comparison between the bed shear stress estimated via the logarithmic model and the momentum integral model, both applied to the varying bottom boundary layer $\delta$ for run A2_05 at Station 1. It can be noted that the free surface gradient $\partial \eta / \partial x$ takes negative values (grey solid line in figure 9a), implying that the free surface is dipping shoreward, for a limited interval of time during uprush. For the remaining of the swash event, it increases eventually tending to the beach slope value of 0.1 at the late backwash. This means that the force generated by the pressure gradients is offshore-directed during the swash event except in a relatively small interval at the early uprush. The momentum integral method generally gives smaller magnitudes of bed shear stresses. Figures $9 \mathrm{~b}$ suggests that the assumptions involved in its derivation preclude a correct estimation of positive (onshoredirected) bed stresses expected during uprush. In particular, the assumptions of negligible advective terms and shear stresses above the boundary layer are likely to be violated at the early stages of uprush. Moreover, additional uncertainties are related to the introduction of a representative $\delta$ during uprush in which the velocity gradient criterion is unable detect the top of the boundary layer. For the phases in which a good agreement between the free surface gradient and the nondimensional free stream acceleration term $-\partial U_{0} /(g \partial t)$ is observed (see figure 9a), the two versions of the momentum integral method MIM_$H_{0}$ and MIM_ $\eta$ provide comparable results. It seems 

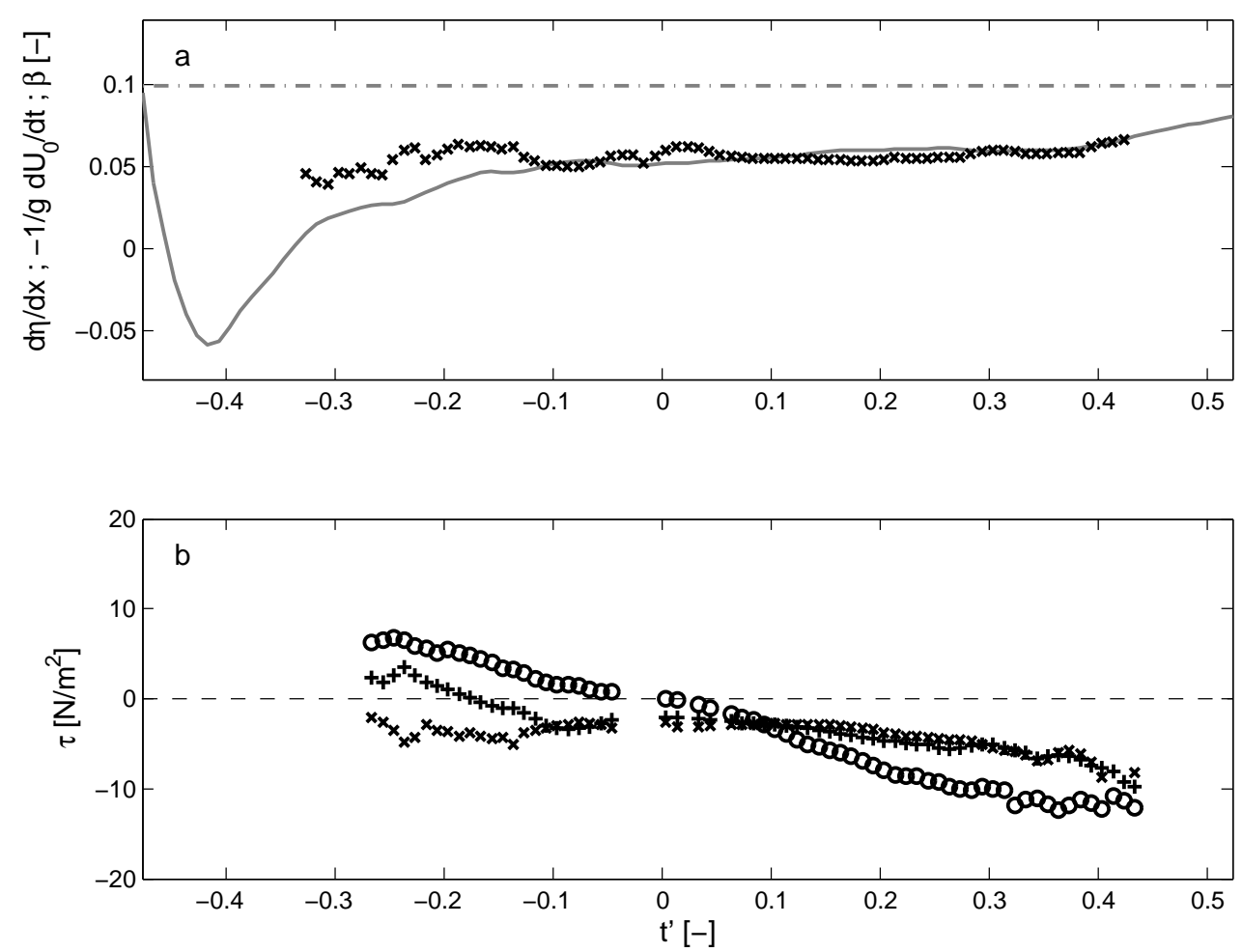

Figure 9: Bed shear stresses estimated by the momentum integral method, run A2_05 at Station 1. a) free surface gradients (solid line), nondimensional free stream acceleration $-\partial U_{0} /(g \partial t)$ (crosses) and bed slope (dash-dotted line); b) bed shear stresses. Circles: logarithmic model; crosses: MIM_$U_{0}$; pluses: MIM_$\eta$.

that, during the uprush, MIM_$U_{0}$ performs worse than MIM_ $\eta$ suggesting that $\partial \eta / \partial x$ is a better proxy than $\partial U_{0} / \partial t$ for the boundary layer pressure gradients $\partial p / \partial x$ at these stages of swash.

\subsection{Effects of axis rotation}

Up to this point, the bed shear stress and the other swash parameters have been derived with respect to a geometrical system with a horizontal $x$ axis. However, the vertical component of fluid velocity in the swash zone can be significant due to the beach slope in the foreshore which is generally larger than that in the rest of the nearshore (Fredsøe and Deigaard, 1992; Svendsen, 2006). In these experiments the swash beach slope varied between 0.09 to 0.13 and its effect is evaluated in this section. The bed parallel velocity $u_{r}$ 

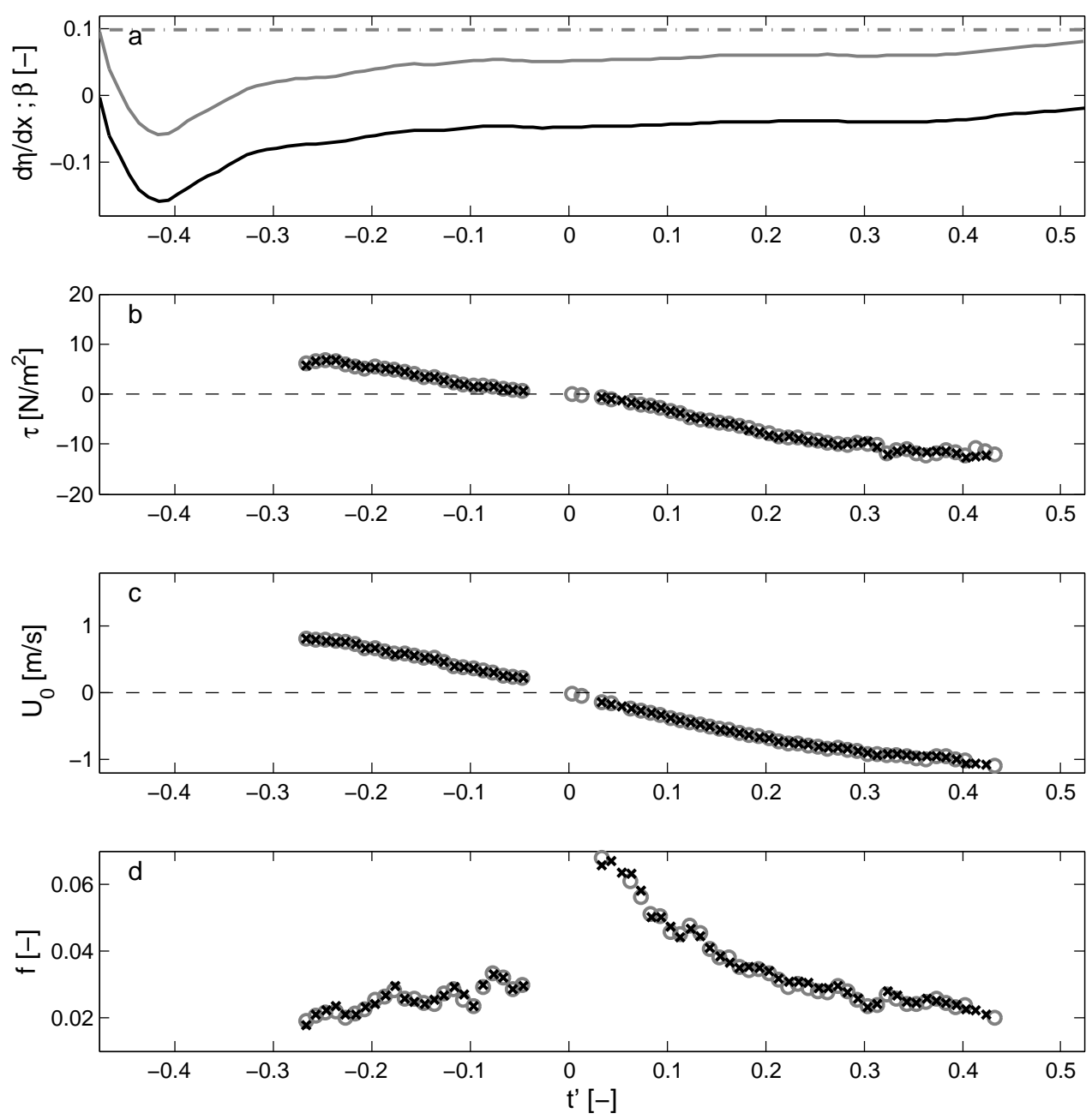

Figure 10: Effects of axis rotation on swash dynamics estimated through the logarithmic model, run A2_05 at Station 1. Gray symbols refer to a coordinate system with an horizontal $x$ axis, black symbols refer to a coordinate system with a bed-parallel $x$ axis. a) free surface gradients (solid lines) and bed slope (dash-dotted line); b) bed shear stress; c) free stream velocity; and d) friction factor.

is:

$$
u_{r}=u \cos (\beta)+w \sin (\beta)
$$

where $w$ is the vertical velocity. The effects of axis rotation on the estimates of swash dynamics using the logarithmic layer analysis are outlined in fig- 
ure 10 for run A2_05 at Station 1. The estimation of bed shear stresses, free stream velocities and friction factors using bed parallel velocities provides minimal discrepancies with respect to the horizontal $x$ axis. Run A4_05 characterized by a steeper beach slope of 0.13 shows similarly small and insignificant differences between the bed shear stresses calculated using bed parallel and horizontal coordinates. These results suggest that vertical components of flow do not play a significant role for beach slopes on the order of 0.1 (between 0.09 and 0.13 in these experiments). Surprisingly, axis rotation also yields minimal differences in the bed shear stress estimated through the momentum integral method (not shown). This is due to the fact that the momentum conservation equation in the bed-parallel direction includes an additional gravitational term $g \sin (\beta)$ which is balanced by the changes in the pressure gradient term $g \partial h / \partial x$ (see figure 10a) brought by the axis rotation.

\section{Discussion}

Near bed velocity profiles have been analyzed in an effort to improve the understanding of the hydrodynamic evolution across the swash phases. Our results confirm and extend previous work dealing with bed shear stress estimation from near-bed velocity measurements. In particular, with respect to the recent work of Kikkert et al. (2012) and Puleo et al. (2012), the boundary layer thickness variation has been taken into account by proposing a velocity gradient criterion. Unfortunately, the large velocity gradients found during uprush even at the uppermost measurement location preclude the identification of the top of the boundary layer for this stage of swash. For this reason, whilst the backwash boundary layer evolution seems to be properly captured by using the described velocity gradient criterion, a representative constant boundary layer thickness equal to the uppermost measurement elevation of the ensemble-averaged event $(2.7 \mathrm{~cm})$ is considered for uprush. The boundary layer variability addressed during backwash seems to provide new insights for the bed stress estimation through the logarithmic and the momentum integral models. By applying the logarithmic model to the near-bed velocities, we obtain a maximum backwash bed shear stress slightly larger than the one observed during the uprush. This difference in the uprush/backwash bed shear stress magnitude in addition to a larger backwash duration seems to lead to an asymmetry and thus to a greater backwash sediment transport potential. However, both the lack of early uprush bed shear stress estimates 
and additional unaccounted processes, such as sediment advection or bore generated turbulence, are likely to compensate this mentioned asymmetry.

In this section we address three important issues related to swash hydrodynamics and bed stress estimation. First, we focus on the effects that the groundwater level induces on swash motions. Then, we investigate the validity of the assumption (involved in the momentum integral method formulation) of small advective terms which can be questioned in the swash zone where shallow flows become progressively unsteady (Fredsøe and Deigaard, 1992; Svendsen, 2006; Puleo et al., 2007). Finally, the variability of friction coefficients and Reynolds numbers during the different phases of swash is considered.

\subsection{Groundwater effects}

It is well accepted that the relative elevation between the beach groundwater table and the sea plays an important role on swash sediment transport and thus morphology evolution (Conley and Inman, 1992; Masselink and Turner, 2012; Turner et al., 2015). Here, the groundwater effects are investigated by considering the runs A2_05 and A4_05 characterized by a high and low lagoon level, respectively. Swash motions were forced by the same incoming wave conditions in these runs. Run A4_05, characterized by a lower lagoon level (see figure 2), has a steeper swash zone slope. In fact, the beach profiler measured a beach slope at Station 2 that changed from 0.08 for run A2_05 to 0.11 for run A4_05 as wave action steepened the beach face during series A. Before carrying out the ensemble averaging process, the time series of the two runs were cross-correlated in order to consider the same swash events in the normalization. A total number of 23 events (identical for the 2 runs) were ensemble averaged.

Figure 11 summarizes swash dynamics for runs A2_05 and A4_05 at Station 2. The mean swash events have similar maximum elevations with a shorter duration of uprush during run A4_05 (the A4_05 swash event starts 0.03 later than the A2_05 event). The steeper slope in run A4_05 yields larger free surface gradients which keep positive values even at the beginning of the uprush phase. Moreover, the larger free stream velocities observed at all stages of swash lead to larger bed shear stress for run A4_05. Comparable friction factor magnitudes are observed for both runs with small differences appreciable at the late backwash in which run A4_05 presents larger values. Figure 11f shows the ensemble-averaged vertical pressure gradients $\partial p / \partial z$ measured by two pressure transducers (PT) near-bed located in the cross 

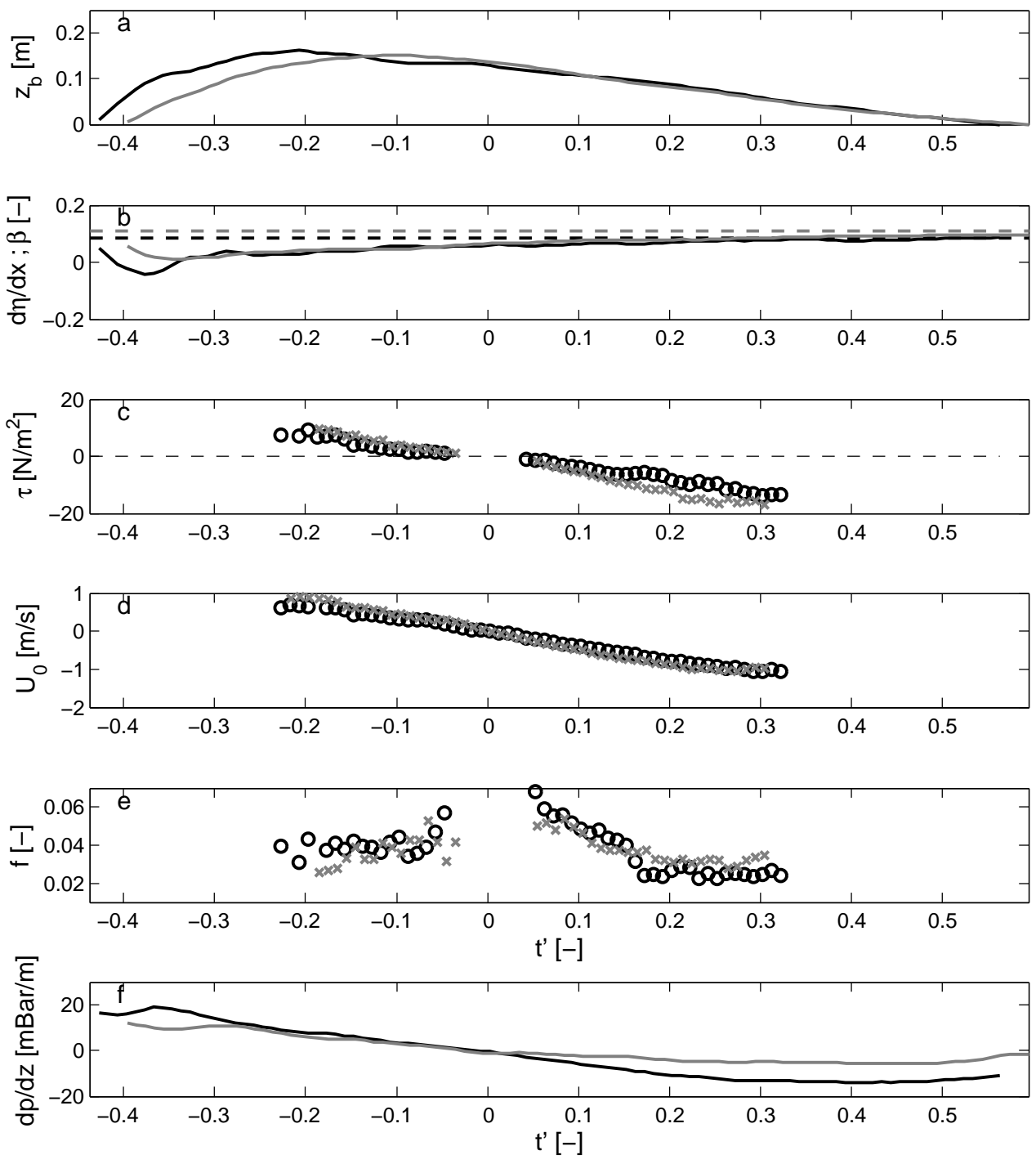

Figure 11: Swash hydrodynamics at Station 2 for high and low lagoon. Black symbols refer to run A2_05 (high lagoon). Grey symbols refer to case A4_05 (low lagoon). a) depth elevations; b) bed slope (dashed line) and free surface gradient(solid line); c) bed shear stress; d) free stream velocity; e) friction factor; and f) vertical pressure gradients.

shore position in the vicinity of the Station 2. Data were corrected for barometric pressure variations and the pore-pressure difference between the upper and lower sensors; $\partial p$ was computed by subtracting the hydrostatic pressure 
offset $(\rho g \partial z)$ between the upper and lower sensors, where $\partial z$ is the vertical sensor separation $(10 \mathrm{~cm})$. For both cases, ensemble-averaged pressure gradients are positive during uprush representing the forcing of a downward directed flux associated with infiltration; the opposite occurs during backwash. Significant differences between the runs are visible especially during the backwash when the larger pressure gradient magnitudes of run A2_05 reveal the presence of pronounced exfiltration processes related with a high groundwater table. Even though it remains difficult to separate the individual role played by exfiltration processes and bed slope changes, these results suggest that the smaller friction factors of run A2_05 are likely to be associated with significant exfiltration processes eventually leading to smaller backwash bed stresses. This seems to confirm and extend the corresponding results observed for gravel barriers during BARDEX (Masselink and Turner, 2012).

\subsection{Advective terms}

The bed shear stresses estimated via the momentum integral method have been compared to those estimated using the logarithmic model. The results show that the momentum integral method fails to address the shorewarddirected bed stress during the uprush and, overall, it provides smaller bed shear stresses than the logarithmic method. These outcomes are likely to be related with the assumptions upon which the momentum integral method relies.

Figure 12 shows the ensemble-averaged advective terms $u \partial u / \partial x$ calculated at Station 1 for run A2_05. Horizontal velocities at Station 1 and 2 are used in order to obtain the horizontal gradient of velocity $\partial u / \partial x$. The advective terms are minimal at flow reversal when velocities turn from positive to negative values. In accordance with the ballistic model (Shen and Meyer, 1963; Guard and Baldock, 2007), the direction of the advective terms is the same as the flow direction (positive during uprush and negative during backwash) as a result of the positive $\partial u / \partial x$ observed at the all stages of swash. The evolution of the ratio $R$ between the advective $u \partial u / \partial x$ and the acceleration $\partial u / \partial t$ terms is plotted in figure 12c. $R$ is smaller than 0.1 over almost the entire swash event and it is negligible at flow reversal. However, at the early uprush and late backwash it takes values of roughly 0.3. Patterns of increasing importance from zero crossing suggest that the magnitude of the advection term may approach that of the acceleration term at the very beginning of the uprush and end of the backwash. Unfortunately, 

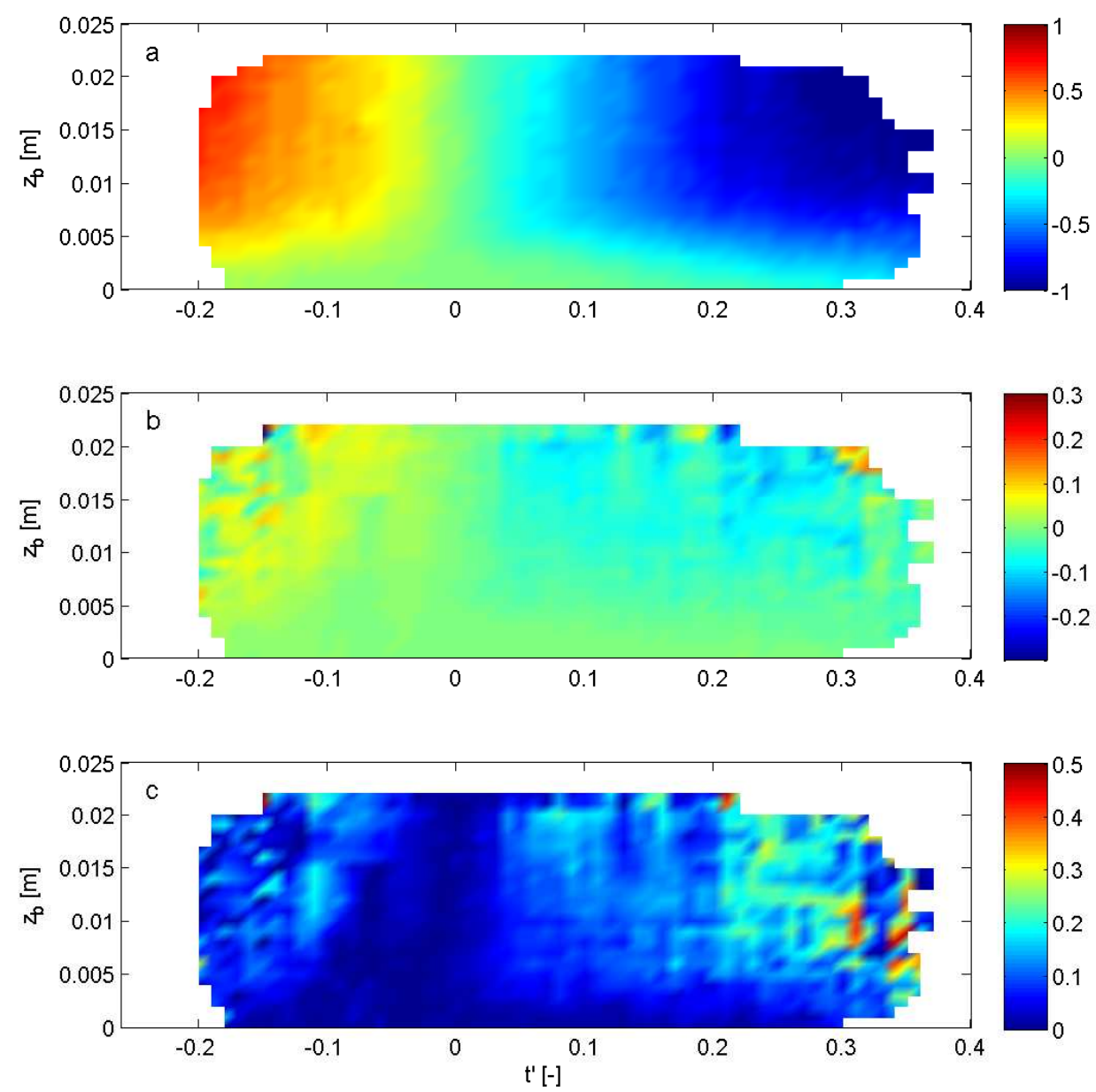

Figure 12: Advection terms in the swash zone, run A2_05 at Station 1. a) Velocity [m/s]; b) Advection terms $\left[\mathrm{m} / \mathrm{s}^{2}\right]$; c) Acceleration versus advection terms ratio [-].

data are missing at these stages of swash when large velocities are expected to lead to an increase of the advective terms. These results suggest that necessary reservations should be made on the validity of the momentum integral method on the swash zone especially at the stages in which large velocities and bed shear stresses are observed. 

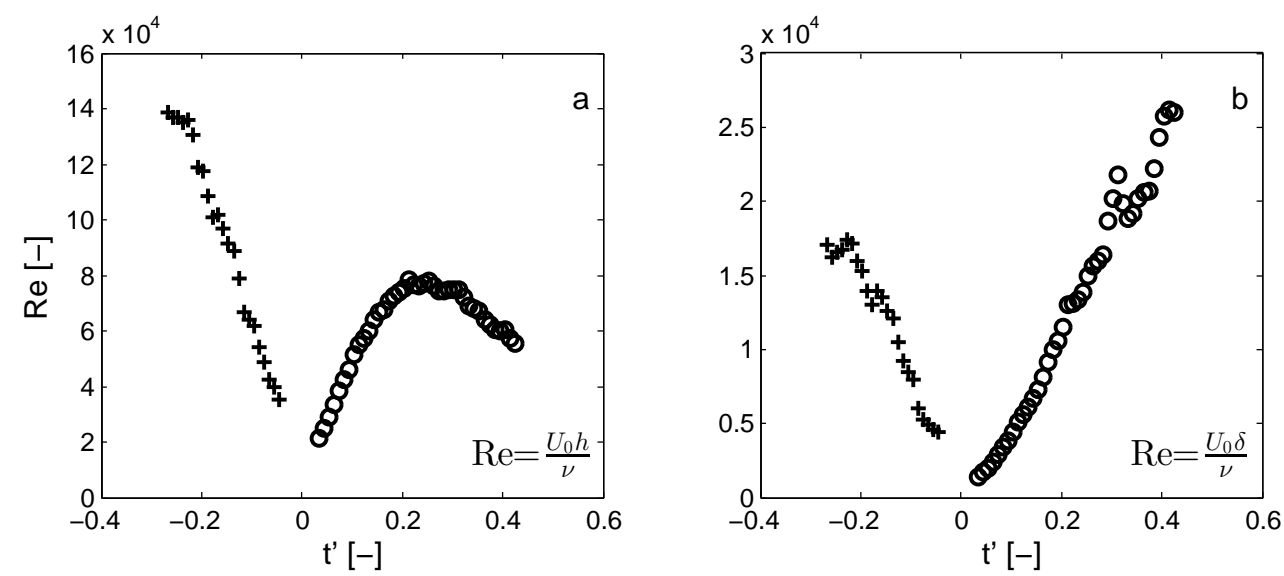

Figure 13: Reynolds number evolution for run A2_05 at Station 1. Pluses: uprush; circles: backwash. a) $l=h$; b) $l=\delta$.
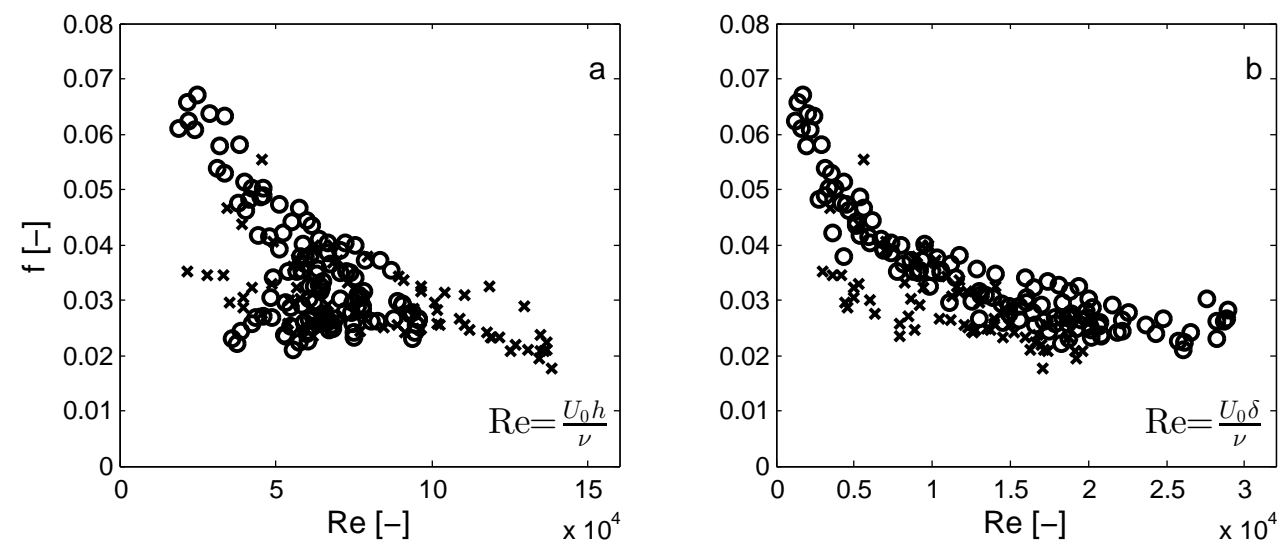

Figure 14: Friction factor as a function of Re for runs A2_05 and A4_05 at Station 1 and 2. Crosses: uprush; circles: backwash. a) $l=h$; b) $l=\delta$.

\subsection{Friction factors}

Figure 13 presents the evolution of the Reynolds numbers for the ensembleaveraged event at Station 1 for run A2_05. The Reynolds number is:

$$
R e=\frac{U_{0} l}{\nu}
$$


where $l$ is a characteristic length scale of the flow. The water depth $h$ is adopted as length scale in figure 13a, whereas figure 13b shows the Reynolds number calculated using the boundary layer thickness $\delta$ as a length scale. The adoption of $\delta$ instead of $h$ as length scale $l$ into equation 19 yields smaller Re along the swash events but it does not affect the uprush behaviour in which the decreasing Re is mainly driven by the decelerating flow. We recall that $\delta$ takes the value of $2.7 \mathrm{~cm}$ corresponding to the uppermost measurement elevation of the ensemble-averaged event during uprush, see section 4.1. At flow reversal, Re approaches zero as a result of minimal velocities. During the backwash, Re (figure 13a) first increases as flow accelerates seaward; however, the progressively shallower water depths in the late stages of backwash lead to an apparent decrease in Re growth followed by a reduction in the later part of the event. On the other hand, due to both the seaward accelerating flow and the boundary layer development, Re (calculated including $\delta$ as length scale) steadily increases during backwash in figure 13b.

The different patterns of Re are reflected in figures 14 which shows the friction factor $f$ as a function of Re for runs A2_05 and A4_05 at Station 1 and 2. Consistent with Kikkert et al. (2012), the slightly increasing values of $f$ (see figure 8) during uprush result in a slight decrease of $f$ for increasing Re. However, it is during backwash that the large $f$ variations are observed (see figure 8) and the choice of the length scale adopted in the Re calculation leads to significant differences in the $f$ behaviour. In particular, figure $14 \mathrm{a}$ shows a friction factor that decreases for the whole backwash phase in which the Re first increases at the beginning of the backwash and then decreases in the late backwash (see figure 13a). On the other hand, by including $\delta$ in the Re calculation, $f$ decreases as Re increases during the whole backwash phase. These results suggest that, by including the boundary layer thickness in the Reynolds number, the friction factor behaviour is consistent to the uniform and steady flow formulation which predicts a decrease of $f$ with increasing Re for laminar and transitional flows. Overall, these results seem to confirm the intuition of Kikkert et al. (2012) who identified the boundary layer development as the main factor in determining the discrepancies between the observed friction factor behaviour (in relation to a Re calculated considering $h$ as a length scale) and the traditional results for steady uniform flows. For larger $\operatorname{Re}\left(\operatorname{Re}>2 \cdot 10^{4}\right.$ in these experiments), the friction factor shows little variability likely related to a transition to a turbulent flow regime. Moreover, for similar Re, the smaller friction factors observed during uprush (than during backwash) may be an indication of an underestimation of the boundary 
layer thickness at this stage of swash. In fact, the representative uprush boundary layer thickness $\delta$, introduced with the main purpose of defining the region of application of the logarithmic and momentum integral models during uprush, is likely to be smaller than the real boundary layer thickness. We consider that this kind of underestimation of the boundary layer thickness has little consequence on the dynamic swash parameter estimation (such as bed shear stress and friction factor) using the logarithmic model. However, an underestimation of the boundary layer thickness would give smaller Re (calculated including $\delta$ as a length scale) which eventually would explain the smaller uprush friction factors observed for similar Re in figure 14b.

\section{Conclusions}

Laboratory experiments were carried out in a large-scale wave flume in which a barrier beach made up of coarse sand and backed by a lagoon was constructed. Acoustic Doppler Velocity Profilers measured high-resolution velocity profiles across the bottom boundary layer in the swash zone. Boundary layer dynamics with a special attention to bed shear stress evolution have been investigated. The main findings are summarized here:

1. The boundary layer thickness for the ensemble-averaged swash event is estimated using a cutoff value of the vertical gradient of the horizontal velocity. The estimation seems to work well during the backwash in which a gradual growth of the boundary layer is observed. However, during uprush uncertainties are due to observed velocity gradients across the measured water column possibly related to bore generated turbulence.

2. The logarithmic model provides the most reliable bed shear stress estimates. Observations show bed stresses at the end of the backwash exceeding the maximum uprush bed stresses recorded a the beginning of the swash event. The observed friction factors are of the same order of magnitude between uprush and backwash with a strong dependency on the boundary layer evolution observed during backwash.

3. The bed stresses estimated via the momentum integral model are compared to those obtained through the logarithmic model. In general terms, the momentum integral method provides smaller bed stresses than the logarithmic model. Moreover, it seems that the onshoredirected stresses during uprush are not properly captured. This deficiency may be attributed to the assumptions of negligible advective 
terms and shear stresses at the top of the boundary layer which may not be satisfied.

4. The effects of a varying groundwater table on swash dynamics are addressed by comparing two runs with same incoming wave conditions and similar beach profile. The smaller backwash friction factors observed in the run with a higher lagoon level are likely to be related with significant exfiltration processes.

5. Logarithmic-model estimated friction coefficients show a considerable variability with the Reynolds numbers especially during backwash. The observed friction coefficient behaviour is consistent with traditional results (Fredsøe and Deigaard, 1992). In particular, the friction factor decreases for increasing Reynolds numbers during the early backwash. For the largest Reynolds numbers observed at the end of the backwash, the friction factor shows little variability consistent with a transition to a turbulent flow regime.

\section{Acknowledgment}

This work was supported by the Engineering and Physical Sciences Research Council of the UK under grant number EP/K000306/1. The BARDEX II experiments described in this publication were supported by the European Community's 7th Framework Programme through the grant to the budget of the Integrating Activity HYDRALAB IV, contract no. 261520. The academic lead of the BARDEX II project was Gerd Masselink and the Deltares coordinator was Guido Wolters.

\section{References}

Aagard, T., Hughes, M. G., 2006. Sediment suspension and turbulence in the swash zone of dissipative beaches. Marine Geology 228, 117-135.

Alsina, J., Caceres, I., 2011. Sediment suspension events in the inner surf and swash zone. measurements in large-scale and high-energy wave conditions. Coast. Eng. 58, 657-670.

Archetti, R., Brocchini, M., 2002. An integral swash zone model with friction: an experimental and numerical investigation. Coastal Eng. 45, 89-110. 
Baldock, T. E., Hughes, M. G., 2006. Field observations of instantaneous water slopes and horizontal pressure gradients in the swash zone. Cont. Shelf Res. 26, 574-588.

Barnes, M. P., Baldock, T., 2010. A lagrangian model for boundary layer growth and bed shear stress in the swash zone. Coast. Eng. 57, 385-396.

Barnes, M. P., O’Donoghue, T., Alsina, J. M., Baldock, T. E., 2009. Direct bed shear stress measurements in bore driven swash. Coast. Eng. 56, 853867.

Briganti, R., Dodd, N., Pokrajac, D., O’Donoghue, T., 2011. Non linear shallow water modelling of bore-driven swash: Description of the bottom boundary layer. Coast. Eng. 58, 463-477.

Butt, T., Tinker, J., Masselink, G., O'Hare, T., Russell, P., 2009. Field observations of sediment fluxes in the inner-surf and swash zones. Journal of Coastal Res. 25, 991-1001.

Conley, D. C., Griffin, J., 2004. Direct measurements of bed stress under swash in the field. J. Geophys. Res. 109.

Conley, D. C., Inman, D. L., 1992. Field observations of the boundary layer under near breaking waves. J. Geophys. Res. 97, 9631-9643.

Cowen, E. A., Sou, I. M., Liu, P.-F., Raubenheimer, B., 2003. Particle image velocimetry measurements within a laboratory generated swash zone. Journal of Engineering mechanics 129(10), 1119-1129.

Foster, D., Carlson, E., Conley, D. C., Puelo, J., 2013. Observations of fluid accelerations within individual swash events. In: Proceedings of the Conference on Coastal Dynamics.

Fredsøe, J., Deigaard, R., 1992. Mechanics of coastal sediment transport. World Scientific.

Guard, P. A., Baldock, T. E., 2007. The influence of seaward boundary conditions on swash zone hydrodynamics. Coast. Eng. 54, 321-331.

Hughes, M. G., Baldock, T. E., 2004. Eulerian flow velocities in the swash zone: Field data and model predictions. J. Geophys. Res. 109 (C8), doi:10.1029/2003JC002213. 
Kikkert, G. A., O’Donoghue, T., Pokrajac, D., Dodd, N., 2012. Experimental study of bore-driven swash hydrodynamics on impermeable rough slopes. Coast. Eng. 60, 149-166.

Masselink, G., Evans, D., Hughes, M. G., Russell, P., 2005. Suspended sediment transport in the swash zone on a dissipative beach. Marine geology 216, 169-189.

Masselink, G., Ruju, A., Conley, D., Turner, I., Ruessink, B. G., Matias, A., Thompson, C., Castelle, B., Wolters, G., 2015. Large-scale Barrier Dynamics Experiment II (BARDEX II): experimental design, instrumentation, test programme and data set. Coast. Eng.Submitted.

Masselink, G., Turner, I. L., 2012. Large-scale laboratory investigation into the effect of varying back-barrier lagoon levels on gravel beach morphology and swash zone sediment transport. Coast. Eng. 63, 23-38.

Mori, N., Suzuki, T., Kakauno, S., 2007. Noise of acoustic doppler velocimeter data in bubbly flows. Jurnal of Engineering Mechanics 133, 122-125.

Nielsen, P., 1992. Coastal Bottom Boundary Layers and Sediment Transport. World Scientific.

Nielsen, P., 2002. shear stress and sediment transport calculations for swash zone modelling. Coastal Eng. 45, 53-60.

Nikuradse, J., 1932. Gesetzmassingket der turbulenten Stromung in glattten Rohren. VDI-Forschungsheft.

O’Donoghue, T., Pokrajac, D., Hondebrink, L., 2010. Laboratory and numerical study of dambreak-generated swash on impermeable slopes. Coast. Eng. 57, 513-530.

Othman, I. K., Baldock, T. E., Callaghan, D. P., 2014. Measurement and modelling of the influence of grain size and pressure gradient on swash uprush sediment transport. Coast. Eng. 83, 1-14.

Pope, S. B., 2000. Turbulent flows. University press, Cambridge, UK.

Puleo, J., Lanckriet, T., Conley, D., Foster, D., 2015. Sediment transport partinioning in the swash zone of a large-scale laboratory beach. Coast. Eng.Submitted. 
Puleo, J. A., Beach, R. A., Holman, R. A., Allen, J. S., 2000. Swash zone sediment suspension and transport and the importance of the bore-generated turbulence. J. Geophys. Res. 105(C7), 17021-17044.

Puleo, J. A., Blelkinsopp, C., Conely, D., Masselink, G., Turner, I., Russel, P., Buscombe, D., Howe, D., Lanckriet, T., McCall, R., Poate, T., 2014a. A comprehensive field study of swash-zone processes, part 1: experimental design with examples of hydrodynamic and sediment transport measurements. Journal of Waterway, Port, Coastal, and Ocean Engineering 140, $14-28$.

Puleo, J. A., Farhadzadeh, A., Kobayashi, N., 2007. Numerical simulation of swash zone fluid accelerations. J. Geophys. Res. 112 (C07007), doi:10.1029/2006JC004084.

Puleo, J. A., Holland, K. T., 2001. Estimating swash zone friction coefficients on a sandy beach. Coast. Eng. 43, 25-40.

Puleo, J. A., Lanckriet, T., Blenkisopp, C., 2014b. Bed level fluctuations in the inner surf and swash zone of a dissipative beach. Marine geology 349, 99-112.

Puleo, J. A., Lanckriet, T., Wang, P., 2012. Near bed cross-shore velocity profiles, bed shear stress and friction on the foreshore of a microtidal beach. Coast. Eng. 68, 6-16.

Sanchez-Arcilla, A., Caceres, I., van Rijn, L., Grune, J., 2011. Revisiting mobile bed tests for beach profile dynamics. Coast. Eng. 58, 583-593.

Shen, M. C., Meyer, R. E., 1963. Climb of a bore on a beach. Part 3. Run-up. J. Fluid Mech. 16, 113-125.

Svendsen, I. A., 2006. Introduction to Nearshore Hydrodynamics. Vol. 24 of Advanced Series on Ocean Engineering. World Scientific, Singapore.

Torres-Freyermuth, A., Puleo, J. A., Pokrajac, D., 2013. Modeling swash-zone hydrodynamics and shear stresses on planar slopes using Reynolds-Averaged Navier-Stokes equations. J. Geophys. Res. 116, doi:10.1029/2010JC006660. 
Turner, I. L., Rau, G. C., Austin, M. J., Andersen, M. S., 2015. Groundwater fluxes and flow paths within coastal barriers: observations from a largescale laboratory experiment (BARDEX II). Coast. Eng.Submitted.

Wei, T., Willmart, W. W., 1989. Reynolds-numbers effects on the structure of turbulent channel flow. J. Fluid Mech. 204, 57-95. 